\title{
Bisphosphonate use and hip fracture epidemiology: ecologic proof from the contrary
}

\author{
This article was published in the following Dove Press journal: \\ Clinical Interventions in Aging \\ 18 November 2010 \\ Number of times this article has been viewed
}

\author{
Alex Fisher ${ }^{1}$ \\ Jodie Martin ${ }^{2}$ \\ Wichat Srikusalanukul ${ }^{2}$ \\ Michael Davis' \\ 'Department of Geriatric Medicine, \\ The Canberra Hospital, Canberra, \\ ACT, Australia; ${ }^{2}$ Australian National \\ University Medical School, Canberra, \\ $\mathrm{ACT}$, Australia
}

Aim: The objective of this article is to evaluate the relationship between the changes in prescriptions of antiosteoporotic drugs (mainly the rapid fall in the use of bisphosphonates [BPs]) and standardized hip fracture (HF) rates over the period 2005-2008 in the Australian Capital Territory (ACT).

Methods: Annual sex- and age-specific HF rates (per 100,000 population) were determined and standardized using the Australian 2006 population census. Data on the annual prescriptions of BPs (mainly alendronate and risedronate), strontium ranelate, and hormone replacement therapy were obtained from the Australian Pharmaceutical Benefits Scheme (PBS) and Repatriation Australian Pharmaceutical Benefits Scheme (RPBS) databases.

Results: In the ACT, the peak annual number of prescriptions for BPs was observed in 2006. Following reports linking osteonecrosis of the jaw with BP use, the number of BP prescriptions dropped by $14 \%$ in 2007-2008 compared with 2005, when the lowest HF rates were recorded. The reduction in BP prescriptions coincided with increased HF rates in females in $2007(+22.6 \%)$ and in $2008(+25.2 \%)$ compared with 2005; in males, HF incidence declined by $6.6 \%$ and $16.7 \%$, respectively. The proportion of filled prescriptions for strontium ranelate, risedronate, and alendronate in 2007-2008 was 1:8.4:15.5, indicating that BPs were the dominant antiosteoporotic drugs. There was an inverse statistically significant relationship between the total annual number of BP prescriptions and standardized HF incidence rates for the 10-year period 1999-2008.

Conclusion: Although currently there is no clear understanding of factors contributing to changing HF epidemiology, the available evidence suggests that much of the decline in HF rates is due to the use of BPs. The fall in the use of BPs is associated with an increase in HF rates in females, indicating that BPs should still be considered the first-line medications for the prevention and treatment of osteoporosis. Our results need to be confirmed in other populations and countries.

Keywords: bisphosphonate use, hip fracture, epidemiology

\section{Introduction}

In the past decade, bisphosphonates (BPs) have become the cornerstone in the treatment of osteoporosis. Their effectiveness in reducing fracture risk, including hip fracture (HF), safety, and good tolerability, has been demonstrated in multiple randomized, placebo-controlled clinical studies. ${ }^{1-4}$ The use of these drugs has also been shown to be cost-effective for the prevention and treatment of fractures associated with osteoporosis in the older adult population. ${ }^{5-7}$ However, the effectiveness of BPs in the general population is less certain. ${ }^{8}$ In a community cohort of postmenopausal women at risk (bone mineral density [BMD] T-score $\leq 2$, or prior fracture), the incidence of fractures
Correspondence: AA Fisher

Department of Geriatric Medicine,

The Canberra Hospital,

PO Box II,Woden ACT 2606, Australia

Tel +6I 262443738

Fax +6I 262444036

Email alex.fisher@act.gov.au 
in patients who received BPs did not differ from those who did not. ${ }^{9}$ A recent study $^{10}$ on HF prevention in long-term care concluded that there is little evidence to apply existing evidence on osteoporosis treatment to this population, as frail older adults are often neglected in clinical trials.

However, in the province of Ontario, Canada, a decrease in wrist fracture and HF rates from 1997 to 2003 was associated with a significant increase in the number of BMD tests with dual-energy X-ray absorptiometry (DXA) and prescriptions of antiresorptive drugs (mainly etidronate). ${ }^{11}$ Similarly, an analysis of a large population of BP users in the United States who were followed for 2 years demonstrated that adherence to BP therapy was associated with significantly fewer osteoporotic fractures, including HFs. ${ }^{12}$ In a previous ecologic study, ${ }^{13}$ we also found that, coincident with increased prescribing of BPs (in Australia, this treatment became widely available in 2000), HF incidence rates progressively declined (statistically significant in females only), and the lowest rates were recorded in 2005 .

When reports linking the use of BPs with osteonecrosis of the jaw (ONJ) were published, subsequent alarmist media coverage had a major effect on patient perceptions about the use of BPs, and widespread fear resulted in discontinuation of BP treatment.

The incidence of ONJ associated with oral BP treatment for osteoporosis has been estimated to be between $<1^{4,14,15}$ and 20-28 $8^{16,17}$ in 100,000 patient-years of exposure. No cases of ONJ have been reported in clinical trials of alendronate, risedronate, and ibandronate for osteoporosis indications. ${ }^{18}$ However, in patients with multiple myeloma, advanced cancer, and metastasis to the skeleton for whom BPs are used in high doses intravenously, the incidence of ONJ may be much higher ( 1 in 1000), specifically after dental procedures (up to $2 \%-12 \%$ at 36 months' exposure). ${ }^{19-22}$

Despite the lack of convincing evidence for a direct causative relationship between ONJ and BPs (especially with low doses used in osteoporosis), a very low incidence of ONJ, and its poorly understood and likely multifactorial pathogenesis, ${ }^{4,16,19,23-26}$ the use of BPs in Australia is decreasing.

The potential impact of this drop in BP use on the incidence of osteoporotic fractures, including HF, is unknown. From the societal perspective, such data are important for a realistic assessment of the real-world effectiveness of current antiosteoporotic and fracture prevention strategies. The aim of this study was to evaluate the relationship between the changes in prescriptions of antiosteoporotic drugs (mainly the rapid fall in the use of BPs) and standardized HF rates over the period 2005-2008.

\section{Materials and methods}

The Australian Capital Territory (ACT) region is well suited for an epidemiological study because all HFs occurring in this area are treated at the Canberra Hospital. In 2008, the ACT had a total population of 352,189 people with $15.1 \%$ aged 60 years and above. ${ }^{27}$ The study was approved by the ACT Human Research Ethics Committee. All the data used for the analysis were anonymous and confidential.

Methods of data collection on HF incidence and antiosteoporotic drugs used were presented in detail in our previous study, which covered the years $1994 / 95$ to $2005 / 06$. $^{13}$ In brief, we utilized the Canberra Hospital electronic administrative database to identify patients discharged with a diagnosis of $\mathrm{HF}$ and excluded all readmissions and reoperations, as well as patients with pathological HF (primary or metastatic bone cancer, multiple myeloma, or Paget's disease). In this study, only cervical and trochanteric fractures of the proximal femur were included, and subtrochanteric and shaft fractures were excluded. Annual sex- and age-specific incidence rates (per 100,000 population) were determined using data from the Australian Bureau of Statistics. Annual HF incidence rates were age- and sex-standardized by the direct method using the Australian 2006 population census as standard. Standardization provides estimates that can be compared directly from one year to another without the confounding effects of the aging of the population and changes in sex distribution.

Data on the annual prescriptions of BPs (mainly alendronate and risedronate), strontium ranelate (approved in Australia in 2006), and hormone replacement therapy (HRT oral or transdermal estrogen only or combined estrogen-progesterone prescriptions) were obtained from the Australian Pharmaceutical Benefits Scheme (PBS) and Repatriation Australian Pharmaceutical Benefits Scheme (RPBS) databases. ${ }^{28}$ All doses of the aforementioned drugs were considered.

The prescriptions analyzed in this dataset (provided under government subsidy) are restricted to two groups: 1) patients aged 70 years or above with demonstrated low BMD (BMD T-score $<-3$ ), and 2) patients with demonstrated fracture due to minimal trauma. Therefore, it can be reasonably postulated that most patients receiving BPs were older adults who are at high risk of fracture. Although private (non-PBS) prescriptions are available, the numbers are low. A marked increase occurred from 2001 when BPs became available as PBS prescriptions. Because vitamin D and calcium supplements are not covered 
by PBS/RPBS and use of raloxifene and parathyroid hormone (PTH) analogs (teriparatide) was minimal, these preparations were not included in the analysis.

\section{Statistical analysis}

Statistical analysis was performed using Stata Version 10 (Stata Corp, College Station, TX, USA). The relationship between $\mathrm{HF}$ incidence rate and antiosteoporotic drugs use was examined by calculation of Pearson's correlation coefficient after logarithmic (log) transformation of variables with skew distribution and by linear regression analysis. All statistical tests were performed at the two-sided $P<0.05$ level of significance.

\section{Results}

\section{Incidence of HF}

Over the 2006-2008 period, the ACT population aged $\geq 60$ years increased by $13.9 \%$ in women and $14.9 \%$ in men, and the number of subjects $\geq 85$ years, which represented $1.2 \%$ of the total ACT population (34.6\% male, $65.36 \%$ female), increased by $15.4 \%$ in women and by $27.3 \%$ in men.

In our region during the last 3 years (2006-2008), there were $494 \mathrm{HFs}$ in older adults ( $\geq 60$ years), and $72.7 \%$ occurred in females. Among females, $53.1 \%$ were aged $\geq 85$ years and, among males, $35.6 \%$ were aged $\geq 85$ years. In females, the annual numbers of HFs and HF rates during this period progressively increased compared with 2005 (Table 1). The crude HF rates among females increased by $11.2 \%$ in 2006 , $16.2 \%$ in 2007 , and $22.6 \%$ in 2008 . The age-specific HF

Table I Annual absolute number of hip fractures, age- and sex-specific and standardized incidence rates of hip fractures in subjects 60 years of age and older

\begin{tabular}{|c|c|c|c|c|}
\hline \multirow{2}{*}{$\frac{\text { Year }}{2005}$} & \multirow{2}{*}{$\begin{array}{l}\text { Sex } \\
F\end{array}$} & \multirow{2}{*}{$\begin{array}{l}\mathbf{N}(\%) \\
91(68.4)\end{array}$} & \multicolumn{2}{|c|}{ Rate/I00,000 person-years } \\
\hline & & & $581.4^{\mathrm{a}}$ & $426.9^{b}$ \\
\hline & M & $42(31.6)$ & $206.6^{\mathrm{a}}$ & $227.6^{\mathrm{b}}$ \\
\hline & Total & $133(100.0)$ & $300.9^{a}$ & $334.4^{b}$ \\
\hline \multirow[t]{3}{*}{2006} & $\mathrm{~F}$ & $105(68.6)$ & $424.1^{\mathrm{a}}$ & $481.8^{\mathrm{b}}$ \\
\hline & M & $48(31.4)$ & $225.3^{\mathrm{a}}$ & $244.8^{b}$ \\
\hline & Total & $153(100.0)$ & $322.1^{\mathrm{a}}$ & $371.7^{\mathrm{b}}$ \\
\hline \multirow[t]{3}{*}{2007} & $\mathrm{~F}$ & $12 \mid(72.9)$ & $443.3^{\mathrm{a}}$ & $506.2^{b}$ \\
\hline & M & $45(27.1)$ & $189.3^{a}$ & $212.6^{b}$ \\
\hline & Total & $166(100.0)$ & $324.9^{a}$ & $364.9^{b}$ \\
\hline \multirow[t]{3}{*}{2008} & $\mathrm{~F}$ & $133(76.0)$ & $467.5^{\mathrm{a}}$ & $534.5^{\mathrm{b}}$ \\
\hline & M & $42(29.0)$ & $169.6^{\mathrm{a}}$ & $189.5^{b}$ \\
\hline & Total & $175(100.0)$ & $328.9^{a}$ & $369.6^{\mathrm{b}}$ \\
\hline Change (\%) & $\mathrm{F}$ & $42(46.2 \%)$ & $+86.1(22.6 \%)^{\mathrm{a}}$ & $+107.6(25.2 \%)^{b}$ \\
\hline from 2005 & M & 0 & $-37.0(-17.9 \%)^{\mathrm{a}}$ & $-38.1(-16.7 \%)^{b}$ \\
\hline to 2008 & Total & $42(31.6 \%)$ & $+28.0(9.3 \%)^{\mathrm{a}}$ & $+35.2(10.5 \%)^{\mathrm{b}}$ \\
\hline
\end{tabular}

Notes: annual age- and sex-adjusted rates (crude); bannual rates standardized to the 2006 Australian population.

Abbreviations: F, female; $M$, male. rates in females increased within each group, with the largest absolute increase in those aged $\geq 85$ years (from 2384.3 to $2567.0 / 100,000$ person-years or $+182.7[7.7 \%] / 100,000$ person-years from 2007 to 2008) and the largest percentage increase in the age group 70-74 years (from 186.0 to $245.4 / 100,000$ person-years or $+31.9 \%$ in 2008 compared with 2007). The age-standardized HF rates, which eliminate the effects of the changes in the population structure over time, demonstrate a slightly higher increase: $12.9 \%$ in $2006,22.6 \%$ in 2007 , and $25.2 \%$ in 2008 compared with 2005.

Among males, the absolute numbers of HFs did not change, but the age-specific rates decreased in 2007 $(-8.4 \%)$ and $2008(-17.9 \%)$ compared with those in 2005. The age-specific HF rates in 2008 compared with 2007 decreased in those aged 75-79 years (from 348.1 to $170.5[-177.6] / 100,000$ person-years, or $-51.0 \%)$ and in the group 80-84 years of age (from 589.1 to 388.2 [-200.9]/100,000 person-years, or $-34.1 \%)$, but increased in those aged $\geq 85$ years (from 854.1 to 1276.0 [+421.9]/100,000 person-years, or $+49.4 \%$ ) and 60-74 years of age (from 48.7 to 57.9 , or $+9.2[+18.9 \%] / 100,000$ person-years). For males, the age-standardized HF rates in 2006 were slightly higher than in $2005(+7.6 \%)$ but lower in $2007(-6.6 \%)$ and $2008(-16.7 \%)$.

Overall in 2008 compared with 2005, age-adjusted HF rates (for females and males) increased by $9.3 \%$, and agestandardized rates increased by $10.5 \%$. The female to male ratio in the standardized $\mathrm{HF}$ rates changed from 1.88 in 2005 to 2.82 in 2008 , indicating a pronounced increase in HF incidence in women.

\section{Use of BPs and other antiosteoporotic medications and $\mathrm{HF}$ incidence}

In the $\mathrm{ACT}$, the peak annual number of prescriptions for BPs was observed in 2006. From 2006 to 2008, there has been a steady decline in the number of filled prescriptions for BPs, from 51,271 (2006) to 45,674 (-10.9\%) in 2008. In total, the number of prescriptions dispensed in the ACT over 2007-2008 dropped by 6927 or by $14 \%$ compared with 2005, when the lowest HF rates were recorded (Figure 1). Over the same period, the number of HRT prescriptions also continued to decline $(-7.6 \%$ in 2007 and $-12.1 \%$ in 2008 compared with 2006). The absolute number of prescriptions for strontium ranelate increased (from 28 in 2006 to 2370 in 2008 ), but this constitutes only $4.02 \%$ of the number of BP prescriptions. The proportion of filled prescriptions for strontium ranelate, risedronate, and alendronate in 2007-2008 


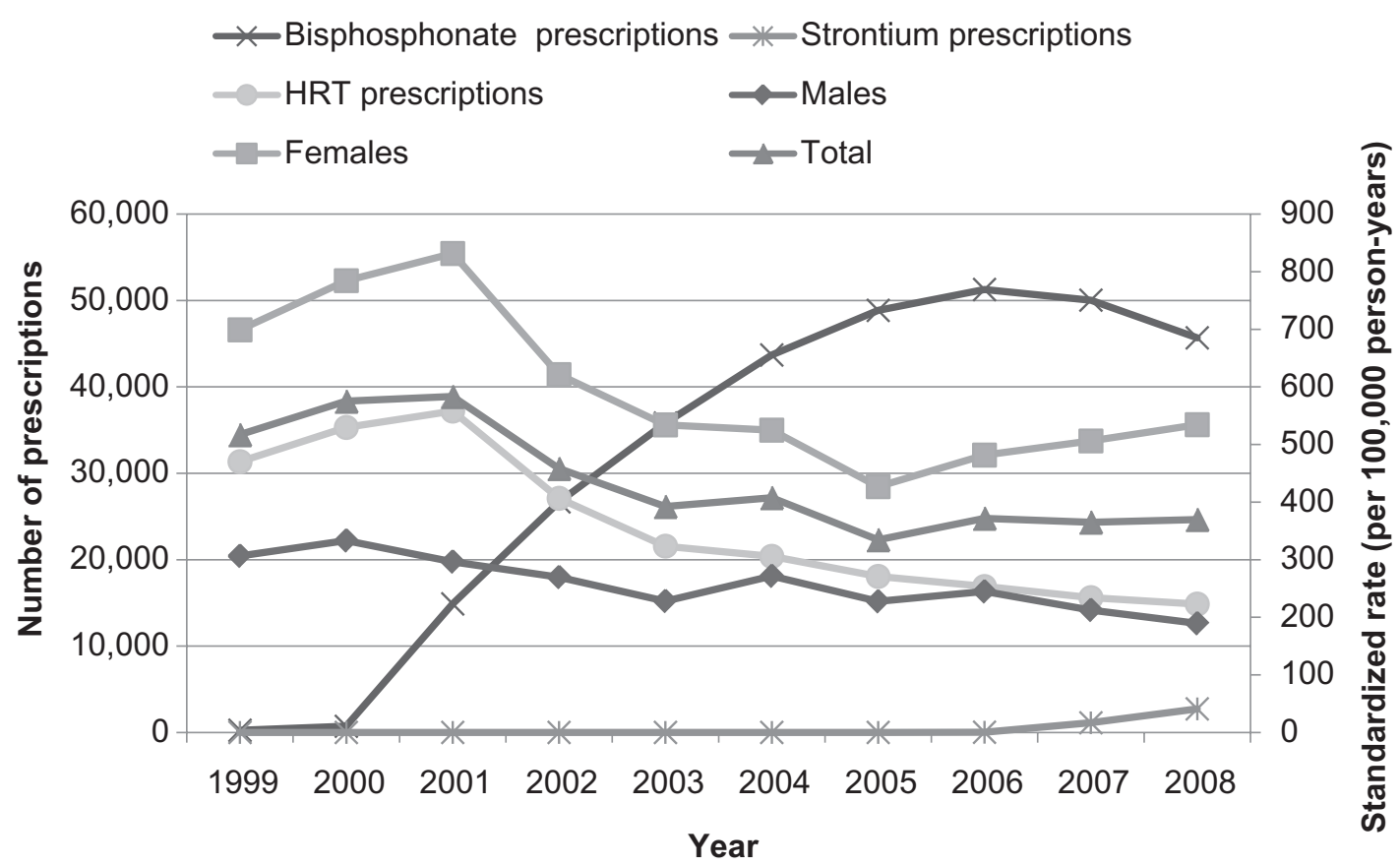

Figure I Age-adjusted and standardized to 2006 Australian population rates of hip fracture in women and men aged $\geq 60$ years and prescriptions of bisphosphonates, strontium ranelate, and hormone replacement therapy in the Australian Capital Territory from 1999 to 2008.

was $1: 8.4: 15.5$, indicating that BPs were the dominant antiosteoporotic drugs. In 2007-2008 compared with 2005, among those aged $\geq 60$ years, the absolute number of HFs increased by 75 (all females), and the number of prescriptions for BPs decreased by 6927 . This corresponds to a drop of 92.4 prescriptions per one 'extra' (unexpected) HF.

Figure 1 shows that changes in the use of antiosteoporotic drugs, especially BPs, were accompanied by inverse changes in standardized HF rates, particularly in females. After 2001, when BP prescriptions started increasing, the HF rates began to decrease, and this downward trend continued up to 2005 , coinciding with a significant increase in BP use. Over the period from 2001 to 2005 , the HF incidence declined in total by $42.6 \%$ (from 583.0 to $248.6 / 100,000$ person-years), $54.1 \%$ in females (from 831.7 to $381.4 / 100,000$ person-years) and $23.2 \%$ in males (from 296.5 to $227.6 / 100,000$ person-years). The reduction in BP prescriptions observed in 2007-2008 was associated with increased HF rates in females, whereas male HF rates continued to decline.

When analyzing the relationship between age-standardized HF rates and BP prescriptions, we calculated Pearson's correlation coefficient and found a significant inverse relationship between the total annual number of BP prescriptions (logtransformed) and HF rates in the total older adult population $(r=-0.735 ; P=0.015)$, in females $(r=-0.668 ; P=0.027)$, and in males $(r=-0.776 ; P=0.008)$. No significant correlation was found for strontium ranelate. Unfortunately, PBS/RPBS data do not include the gender of the population filling prescriptions for antiosteoporotic medications, so we were unable to analyze the use of BPs separately by females and males.

Linear regression analysis of the relationship between the number of BP prescriptions and standardized HF rates from 1999 to 2008 confirmed the inverse relationship (Table 2). As illustrated in Figure 2, higher BP use was associated with significantly lower HF rates.

\section{Discussion}

The main finding of this ecologic study is an inverse statistically significant relationship between use of osteoporosis treatment, namely the total annual number of BP prescriptions, and standardized HF incidence rates for the 10-year period 1999-2008.

Table 2 Linear regression analysis between the number of bisphosphonate prescriptions $\left(\times 10^{3}\right)$ and age-standardized hip fracture rates (per 100,000 person-years) in the elderly in 1999-2008 in the Australian Capital Territory

\begin{tabular}{llllll}
\hline & Coefficient & SE & $\mathbf{9 5 \%} \mathbf{C l}$ & $\boldsymbol{P}$ value & $\boldsymbol{R}^{2}$ adjusted \\
\hline Females & -60.43 & 1.054 & -8.473 to & $<0.001$ & 0.780 \\
& & & -3.613 & & \\
Males & -1.554 & 0.403 & -2.882 to & 0.001 & 0.715 \\
& & & -1.026 & & \\
Total & -4.188 & 0.616 & -5.610 to & $<0.001$ & 0.834 \\
& & & -2.767 & & \\
\hline
\end{tabular}

Abbreviations: SE, standard error; $\mathrm{Cl}$, confidence interval. 
A)

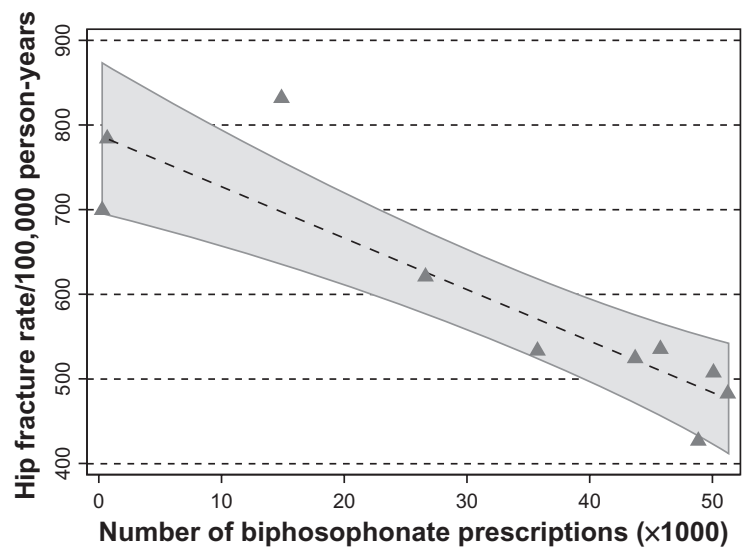

B)

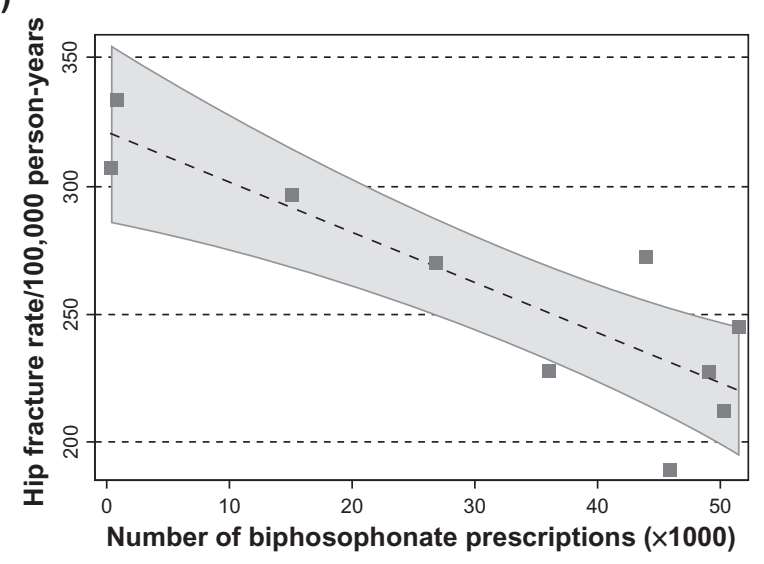

C)

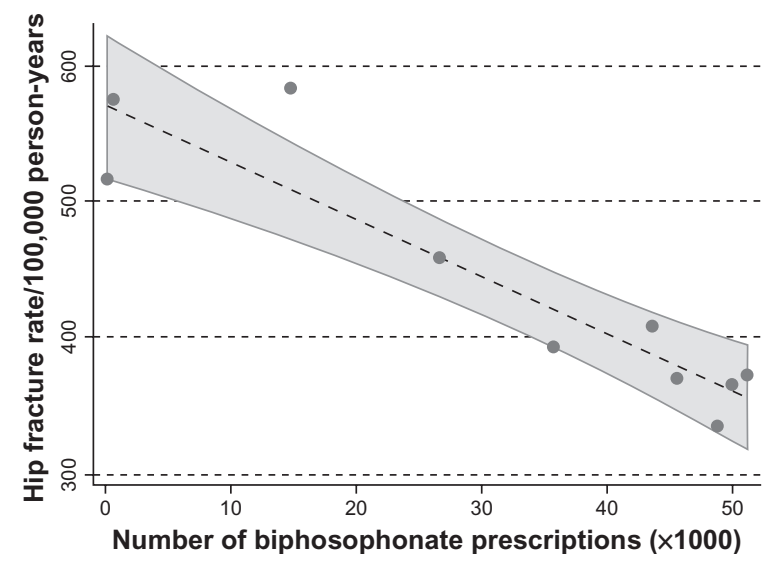

Figure 2 The relationship between the total annual number of prescriptions $\left(\times 10^{3}\right)$ for bisphosphonates and age-standardized hip fracture rates (per 100,000 personyears) in A) females, B) males, and C) the total elderly population in the Australian Capital Territory (1999-2008). Regression lines with 95\% confidence intervals.

Over the last decade, advances in molecular and cellular biology of bone remodeling have revealed new targets for and novel pharmacological approaches to therapies for osteoporosis. Newer agents include strontium ranelate (capable of both inhibiting bone resorption and increasing bone formation), ${ }^{29,30}$ new-generation selective estrogen receptor modulators lasofoxifene ${ }^{31}$ and bazedoxifene, ${ }^{32}$ anabolic agents (PTH and its analogs, monoclonal antibody to sclerostin), ${ }^{33-36}$ and antiresorptive agents such as RANK signaling inhibitors (denosumab), cathepsin $\mathrm{K}$ inhibitors (odanacatib, balicatib, and relacatib), and antagonists of $\alpha(v) \beta(3)$ integrin (L-000845704). ${ }^{34,37-39}$ Although the newer and emerging therapies as well as combined treatments (eg, with alfacalcidol) $)^{2}$ may be more potent and targetspecified, ${ }^{2,33,37,40,41}$ currently, nitrogen-containing BPs, antiresorptive agents shown to reduce fracture risk by $\sim 50 \%$ at best, ${ }^{42}$ remain the mainstay for pharmacological treatment of osteoporosis., ${ }^{4,43-46}$ The antiresorptive action of BPs as a class results from both reduced osteoclastic activity (by inhibiting an enzyme farnesyl pyrophosphate synthase) and affinity for bone mineral, but the antiresorptive potency and binding affinity differ among the compounds.

We focused on the BPs because the prevalence of use of other antiosteoporotic drugs over this period was too low to detect an effect on HF incidence. After 2000, when BPs became widely available in Australia, the number of prescriptions steadily increased up to 2006. Between 2001 and 2005, the HF incidence declined in older females ( $\geq 60$ years) by $54.1 \%$, in males by $23.2 \%$, and in total by $42.6 \%$. These findings are in agreement with those reported from Canada: ${ }^{11} \mathrm{a}$ decline of HF rates with a steady increase in etidronate use between 1996 and 2003.

The new and intriguing observation of this study is that the substantial fall in BP use (following reports on ONJ associated with BPs) since 2006 coincides with increased standardized HF rates in females in $2007(+22.6 \%)$ and in $2008(+25.2 \%)$ compared with 2005 , whereas, in males, HF incidence declined in the same period. Older females are known to comprise the majority of BP users, whereas male osteoporosis is much less frequently recognized and treated. ${ }^{47,48}$ Our observations are in line with data showing an inverse relation between adherence to BP and fracture rate. High adherence to BP therapy was associated with a $23 \%$ reduction in $\mathrm{HF}$ rates ${ }^{49}$ and poor compliance resulted in a $28 \%$ increased HF risk. ${ }^{50}$ A recently published Australian study concluded that, in 2008 , a $13.2 \%$ estimated reduction in the number of BP prescriptions may have resulted in $70(+16.9 \%)$ HFs and 14 deaths. ${ }^{51}$ Importantly, BPs not only effectively prevent fragility fractures but also improve quality of life ${ }^{52}$ and reduce the risk of breast cancer in postmenopausal women, ${ }^{53,54}$ as well as reduce all-cause mortality. ${ }^{55-57}$

The fact that reduction in $\mathrm{BP}$ prescriptions was followed by an increase in HF rates in females, along with 
the previously observed decline in HF rates when BP use rapidly increased, does not necessarily establish a causal connection between the two. Other factors may also have contributed to the short-term changes in HF incidence rates. Indeed, trends toward decreasing HF rates were observed in some countries (United States, Canada, and Sweden) before widespread availability of current antiosteoporotic medications. ${ }^{8,58-60}$ No consistent changes or even increasing HF trends were recently reported in other developed countries (Germany, Austria, Finland, Switzerland, and Japan), ${ }^{61-65}$ and some found declining HF incidence only in the new millennium, ${ }^{11,61,66,67}$ although none of these studies, except one, ${ }^{11}$ provided information on BP use.

The continuing fall in the use of HRT since 2001 is unlikely to account for the increase in HF incidence in females in 2007-2008, as in the previous period (2001-2005), despite HRT prescriptions having decreased by half and HF rates having declined by $54.1 \%$.

Different patterns in HF rates seen in males and females may argue against the role of BPs. In contrast to some recent studies ${ }^{61}$ reporting no downward trend in the HF rates in males, but in accordance with others, ${ }^{59}$ we found a reduction in HF incidence in males in 2007-2008 despite the drop in BP prescriptions. This is difficult to interpret. As men are rarely treated for osteoporosis, the reduction in use of BPs may be too small to lead to a detectable decrease in HF rates. Other factors possibly associated with a decrease in HF rates in males may include overweight and obesity, declining smoking rates, ${ }^{68}$ and a birth cohort effect. ${ }^{69}$ These explanations are still hypothetical. The complex relationship between $\mathrm{HF}$ and gender requires further investigations.

This study has certain limitations in addition to its ecologic design. No information was available on individual demographic and clinical characteristics of BP users. Similarly, the proportion of patients receiving adequate antiosteoporotic therapy (including calcium and vitamin D supplementation) is unknown. There is also a possibility that the medication was prescribed but not taken. On the other hand, because of the remaining effect of BP on fracture risk after cessation of treatment, ${ }^{70,71}$ it is likely that a short-term study, like ours, underestimates the impact of the current fall in BP use on HF rates. Despite these limitations, our ecological analysis provides strong support for the antifracture effectiveness of BPs in real-world practice.

In conclusion, although currently there is no clear understanding of factors contributing to changing $\mathrm{HF}$ epidemiology, the available evidence suggests that much of the decline in HF rates is due to the use of BPs. A fall in the use of BPs is associated with increased HF rates in females, indicating that BPs should still be considered the first-line medications for the prevention and treatment of osteoporosis. Our results need to be confirmed in other populations and countries.

\section{Acknowledgment}

The authors gratefully acknowledge Novartis Pharmaceuticals for supporting the publishing of this manuscript after its acceptance by the journal. The sponsor did not influence this manuscript in any way and played no role in the design of the study; the collection, analysis, or interpretation of data; or the preparation of the manuscript.

\section{Disclosure}

Dr M Davis has received honoraria from Sanofi Aventis, Servier, and Merck Sharp \& Dohme for presentations at scientific educational sessions. The three other authors have no conflicts of interest to declare.

\section{References}

1. Harris ST, Reginster JY, Harley C, et al. Risk of fracture in women treated with monthly oral ibandronate or weekly bisphosphonates: the eValuation of IBandronate Efficacy (VIBE) database fracture study. Bone. 2009;44(5):758-765.

2. Ringe JD, Doherty JG. Absolute risk reduction in osteoporosis: assessing treatment efficacy by number needed to treat. Rheumatol Int. 2010; 30(7):863-869.

3. Stevenson M, Jones ML, de Nigris E, Brewer N, Davis S, Oakley J. A systematic review and economic evaluation of alendronate, etidronate, risedronate, raloxifene and teriparatide for the prevention and treatment of postmenopausal osteoporosis. Health Technol Assess. 2005; $9(22): 1-160$.

4. Watts NB, Diab DL. Long-term use of bisphosphonates in osteoporosis. J Clin Endocrinol Metab. 2010;95(4):1555-1565.

5. Borgstrom F, Strom O, Coelho J, et al. The cost-effectiveness of risedronate in the UK for the management of osteoporosis using the FRAX. Osteoporos Int. 2010;21(3):495-505.

6. Kanis JA, Adams J, Borgstrom F, et al. The cost-effectiveness of alendronate in the management of osteoporosis. Bone. 2008;42(1):4-15.

7. Tosteson AN, Melton LJ 3rd, Dawson-Hughes B, et al. Cost-effective osteoporosis treatment thresholds: the United States perspective. Osteoporos Int. 2008;19(4):437-447.

8. Melton LJ 3rd, Kanis JA, Johnell O. Potential impact of osteoporosis treatment on hip fracture trends. J Bone Miner Res. 2005;20(6):895-897.

9. Feldstein AC, Weycker D, Nichols GA, et al. Effectiveness of bisphosphonate therapy in a community setting. Bone. 2009;44(1): 153-159.

10. Crilly RG, Hillier LM, Mason M, Gutmanis I, Cox L. Prevention of hip fractures in long-term care: relevance of community-derived data. J Am Geriatr Soc. 2010;58(4):738-745.

11. Jaglal SB, Weller I, Mamdani M, et al. Population trends in BMD testing, treatment, and hip and wrist fracture rates: are the hip fracture projections wrong? J Bone Miner Res. 2005;20(6):898-905.

12. Siris ES, Harris ST, Rosen CJ, et al. Adherence to bisphosphonate therapy and fracture rates in osteoporotic women: relationship to vertebral and nonvertebral fractures from 2 US claims databases. Mayo Clin Proc. 2006;81(8):1013-1022. 
13. Fisher AA, O'Brien ED, Davis MW. Trends in hip fracture epidemiology in Australia: possible impact of bisphosphonates and hormone replacement therapy. Bone. 2009;45(2):246-253.

14. Khosla S, Burr D, Cauley J, et al. Bisphosphonate-associated osteonecrosis of the jaw: report of a task force of the American Society for Bone and Mineral Research. J Bone Miner Res. 2007;22(10):1479-1491.

15. Pazianas M, Miller P, Blumentals WA, Bernal M, Kothawala P. A review of the literature on osteonecrosis of the jaw in patients with osteoporosis treated with oral bisphosphonates: prevalence, risk factors, and clinical characteristics. Clin Ther. 2007;29(8):1548-1558.

16. Abrahamsen B. Bisphosphonate adverse effects, lessons from large databases. Curr Opin Rheumatol. 2010;22(4):404-409.

17. Lo JC, O'Ryan FS, Gordon NP, et al. Prevalence of osteonecrosis of the jaw in patients with oral bisphosphonate exposure. J Oral Maxillofac Surg. 2010;68(2):243-253.

18. Pazianas M, Cooper C, Ebetino FH, Russell RG. Long-term treatment with bisphosphonates and their safety in postmenopausal osteoporosis. Ther Clin Risk Manag. 2010;6:325-343.

19. Khan AA, Sandor GK, Dore E, et al. Bisphosphonate associated osteonecrosis of the jaw. J Rheumatol. 2009;36(3):478-490.

20. Mavrokokki T, Cheng A, Stein B, Goss A. Nature and frequency of bisphosphonate-associated osteonecrosis of the jaws in Australia. J Oral Maxillofac Surg. 2007;65(3):415-423.

21. Walter C, Al-Nawas B, Frickhofen N, et al. Prevalence of bisphosphonate associated osteonecrosis of the jaws in multiple myeloma patients. Head Face Med. 2010;6:11.

22. Woo SB, Hellstein JW, Kalmar JR. Narrative [corrected] review: bisphosphonates and osteonecrosis of the jaws. Ann Intern Med. 2006; 144(10):753-761.

23. Khan AA, Sandor GK, Dore E, et al. Canadian consensus practice guidelines for bisphosphonate associated osteonecrosis of the jaw. J Rheumatol. 2008;35(7):1391-1397.

24. Rizzoli R, Burlet N, Cahall D, et al. Osteonecrosis of the jaw and bisphosphonate treatment for osteoporosis. Bone. 2008;42(5):841-847.

25. Sambrook PN, Ebeling P. Osteonecrosis of the jaw. Curr Rheumatol Rep. 2008;10(2):97-101.

26. Silverman SL, Landesberg R. Osteonecrosis of the jaw and the role of bisphosphonates: a critical review. Am J Med. 2009; 122 Suppl 2:S33-S45.

27. Australian Bureau of Statistics. Australian Demographic Statistics. Population Projections. Catalogue No 3101.0. Canberra (ACT): Australian Bureau of Statistics; 2009.

28. Medicare Australia. PBS Statistics. 2010. Available from: http://www medicareaustralia.gov.au/provider/pbs/stats.jsp. Accessed 2010 Oct 29.

29. Deeks ED, Dhillon S. Spotlight on strontium ranelate: in postmenopausal osteoporosis. Drugs Aging. 2010;27(9):771-773.

30. Marie PJ, Felsenberg D, Brandi ML. How strontium ranelate, via opposite effects on bone resorption and formation, prevents osteoporosis Osteoporos Int. 2010 Sep 2. [Epub ahead of print].

31. Gennari L, Merlotti D, Nuti R. Selective estrogen receptor modulator (SERM) for the treatment of osteoporosis in postmenopausal women: focus on lasofoxifene. Clin Interv Aging. 2010;5:19-29.

32. Kung AW, Chu EY, Xu L. Bazedoxifene: a new selective estrogen receptor modulator for the treatment of postmenopausal osteoporosis. Expert Opin Pharmacother. 2009;10(8):1377-1385.

33. Canalis E. Update in new anabolic therapies for osteoporosis. J Clin Endocrinol Metab. 2010;95(4):1496-1504.

34. Deal C. Future therapeutic targets in osteoporosis. Curr Opin Rheumatol. 2009;21(4):380-385.

35. Fabbriciani G, Pirro M, Manfredelli MR, et al. Transient osteoporosis of the hip: successful treatment with teriparatide. Rheumatol Int. 2010 Mar 18. [Epub ahead of print].

36. Li X, Warmington KS, Niu QT, et al. Inhibition of sclerostin by monoclonal antibody increases bone formation, bone mass and bone strength in aged male rats. J Bone Miner Res. 2010 Jul 16. [Epub ahead of print]
37. Jules J, Ashley JW, Feng X. Selective targeting of RANK signaling pathways as new therapeutic strategies for osteoporosis. Expert Opin Ther Targets. 2010;14(9):923-934.

38. Palaniswamy C, Selvaraj DR, Rao V, Patel U. Newer therapies for osteoporosis. Am J Ther. 2010;17(2):197-200.

39. Roux S. New treatment targets in osteoporosis. Joint Bone Spine. 2010; $77(3): 222-228$.

40. Inderjeeth CA, Foo AC, Lai MM, Glendenning P. Efficacy and safety of pharmacological agents in managing osteoporosis in the old old: review of the evidence. Bone. 2009;44(5):744-751.

41. Salari Sharif P, Abdollahi M, Larijani B. Current, new and future treatments of osteoporosis. Rheumatol Int. 2010 Jul 30. [Epub ahead of print].

42. Liberman UA, Hochberg MC, Geusens P, et al. Hip and non-spine fracture risk reductions differ among antiresorptive agents: evidence from randomised controlled trials. Int J Clin Pract. 2006; 60(11): 1394-1400.

43. Abelson A, Ringe JD, Gold DT, Lange JL, Thomas T. Longitudinal change in clinical fracture incidence after initiation of bisphosphonates. Osteoporos Int. 2010;21(6):1021-1029.

44. Le Goff B, Guillot P, Glemarec J, Berthelot JM, Maugars Y. A comparison between bisphosphonates and other treatments for osteoporosis. Curr Pharm Des. 2010;16(27):3037-3044.

45. MacLean C, Newberry S, Maglione M, et al. Systematic review: comparative effectiveness of treatments to prevent fractures in men and women with low bone density or osteoporosis. Ann Intern Med. 2008;148(3):197-213.

46. Masud T, McClung M, Geusens P. Reducing hip fracture risk with risedronate in elderly women with established osteoporosis. Clin Interv Aging. 2009;4:445-449.

47. Feldstein AC, Nichols G, Orwoll E, et al. The near absence of osteoporosis treatment in older men with fractures. Osteoporos Int. 2005; 16(8):953-962.

48. Papaioannou A, Kennedy CC, Ioannidis G, et al. The osteoporosis care gap in men with fragility fractures: the Canadian Multicentre Osteoporosis study. Osteoporos Int. 2008;19(4):581-587.

49. Patrick AR, Brookhart MA, Losina E, et al. The complex relation between bisphosphonate adherence and fracture reduction. J Clin Endocrinol Metab. 2010;95(7):3251-3259.

50. Imaz I, Zegarra P, Gonzalez-Enriquez J, Rubio B, Alcazar R, Amate JM. Poor bisphosphonate adherence for treatment of osteoporosis increases fracture risk: systematic review and meta-analysis. Osteoporos Int. 2010;21(11):1943-1951.

51. Sambrook PN, Chen JS, Simpson JM, March LM. Impact of adverse news media on prescriptions for osteoporosis: effect on fractures and mortality. Med J Aust. 2010;193(3):154-156.

52. Kawate H, Ohnaka K, Adachi M, et al. Alendronate improves QOL of postmenopausal women with osteoporosis. Clin Interv Aging. 2010;5: $123-131$.

53. Chlebowski RT, Chen Z, Cauley JA, et al. Oral bisphosphonate use and breast cancer incidence in postmenopausal women. J Clin Oncol. 2010;28(22):3582-3590.

54. Rennert G, Pinchev M, Rennert HS. Use of bisphosphonates and risk of postmenopausal breast cancer. J Clin Oncol. 2010;28(22): 3577-3581.

55. Bolland MJ, Grey AB, Gamble GD, Reid IR. Effect of osteoporosis treatment on mortality: a meta-analysis. J Clin Endocrinol Metab. 2010;95(3):1174-1181.

56. Cree MW, Juby AG, Carriere KC. Mortality and morbidity associated with osteoporosis drug treatment following hip fracture. Osteoporos Int. 2003;14(9):722-727.

57. Lyles KW, Colon-Emeric CS, Magaziner JS, et al. Zoledronic acid in reducing clinical fracture and mortality after hip fracture. $N$ Engl J Med. 2007;357:nihpa40967.

58. Gehlbach SH, Avrunin JS, Puleo E. Trends in hospital care for hip fractures. Osteoporos Int. 2007;18(5):585-591. 
59. Leslie WD, O’Donnell S, Jean $\mathrm{S}$, et al. Trends in hip fracture rates in Canada. JAMA. 2009;302(8):883-889.

60. Lofman O, Berglund K, Larsson L, Toss G. Changes in hip fracture epidemiology: redistribution between ages, genders and fracture types. Osteoporos Int. 2002;13(1):18-25.

61. Chevalley T, Guilley E, Herrmann FR, Hoffmeyer P, Rapin CH, Rizzoli R. Incidence of hip fracture over a 10-year period (1991-2000): reversal of a secular trend. Bone. 2007;40(5):1284-1289.

62. Hagino H, Katagiri H, Okano T, Yamamoto K, Teshima R. Increasing incidence of hip fracture in Tottori Prefecture, Japan: trend from 1986 to 2001. Osteoporos Int. 2005;16(12):1963-1968.

63. Icks A, Haastert B, Wildner M, Becker C, Meyer G. Trend of hip fracture incidence in Germany 1995-2004: a population-based study. Osteoporos Int. 2008;19(8):1139-1145.

64. Lonnroos E, Kautiainen H, Karppi P, et al. Increased incidence of hip fractures. A population based-study in Finland. Bone. 2006; 39(3):623-627.

65. Mann E, Icks A, Haastert B, Meyer G. Hip fracture incidence in the elderly in Austria: an epidemiological study covering the years 1994 to 2006. BMC Geriatr. 2008;8:35.
66. Dimai HP, Svedbom A, Fahrleitner-Pammer A, et al. Epidemiology of hip fractures in Austria: evidence for a change in the secular trend. Osteoporos Int. 2010 May 11. [Epub ahead of print].

67. Hernandez JL, Olmos JM, Alonso MA, et al. Trend in hip fracture epidemiology over a 14-year period in a Spanish population. Osteoporos Int. 2006;17(3):464-470.

68. Kanis JA, Johnell O, Oden A, et al. Smoking and fracture risk: a metaanalysis. Osteoporos Int. 2005;16(2):155-162.

69. Kannus P, Niemi S, Parkkari J, Palvanen M, Vuori I, Järvinen M. Nationwide decline in incidence of hip fracture. $J$ Bone Miner Res. 2006;21(12):1836-1838.

70. Ensrud KE, Barrett-Connor EL, Schwartz A, et al. Randomized trial of effect of alendronate continuation versus discontinuation in women with low BMD: results from the Fracture Intervention Trial long-term extension. J Bone Miner Res. 2004;19(8):1259-1269.

71. Black DM, Schwartz AV, Ensrud KE, et al. Effects of continuing or stopping alendronate after 5 years of treatment: the Fracture Intervention Trial Long-term Extension (FLEX): a randomized trial. JAMA. 2006; 296(24):2927-2938.
Clinical Interventions in Aging

\section{Publish your work in this journal}

Clinical Interventions in Aging is an international, peer-reviewed journal focusing on evidence-based reports on the value or lack thereof of treatments intended to prevent or delay the onset of maladaptive correlates of aging in human beings. This journal is indexed on PubMed Central, MedLine, the American Chemical Society's 'Chemical Abstracts Ser-

\section{Dovepress}

vice' (CAS), Scopus and the Elsevier Bibliographic databases. The manuscript management system is completely online and includes a very quick and fair peer-review system, which is all easy to use. Visit $\mathrm{http}: / / \mathrm{www}$.dovepress.com/testimonials.php to read real quotes from published authors. 